\title{
Émile Benveniste e a dupla significância da língua: a distinção semiótico/semântico
}

Heloísa Monteiro Rosário*

\section{Resumo}

Este trabalho trata especificamente da dupla significância da língua, ou seja, das noções de semiótico e semântico formuladas por Émile Benveniste nos artigos "A forma e o sentido na linguagem" (1967; 1974) e "Semiologia da língua” (1969; 1974). Objetiva-se, de um lado, discutir a distinção semiótico/semântico (salientando-a em uma perspectiva linguística e outra semiológica) e, de outro, estabelecer uma relação entre o final programático proposto pelo linguista em "Semiologia da língua" e as noções de semiótico e semântico. Para tanto, além dos artigos citados, são mobilizados outros textos de seus Problemas de linguistica geral (1966/1995; 1974/1989) em contraponto com a publicação Últimas aulas no Collège de France (1968 e 1969) (2012/2014), obra estabelecida geneticamente a partir de manuscritos do linguista e de seus ouvintes.

Palavras-chave: Émile Benveniste. (Dupla) Significância. Semiótico. Semântico. Semiologia da língua.

\section{Introdução}

As noções de semiótico e semântico, que configuram a dupla significância da língua, são fundamentais na reflexão desenvolvida por Émile Benveniste em seu artigo Semiologia da língua, texto encomendado por Julia Kristeva para o primeiro número da revista Semiotica em 1969.

Apresento, neste trabalho, uma parte da discussão de Semiologia da língua proposta em minha tese de Doutorado, orientada pelo professor Valdir Flores, e recentemente defendida - "Um périplo benvenistiano: o semiólogo e a semiologia da língua" (ROSÁRIO, 2018).

Nessa pesquisa, através de um estudo teórico de diferentes textos de seus Problemas de linguística geral (1966/1995;

\footnotetext{
Licenciada em Letras (Português-Francês) pela Universidade Federal do Rio Grande do Sul (UFRGS). Especialista em Estudos Linguísticos do Texto, Mestre e Doutora em Estudos da Linguagem pelo Programa de Pós-Graduação em Letras da Ufrgs. Professora do Departamento de Línguas Modernas do Instituto de Letras da Ufrgs. E-mail: heloisa.monteirorosario@ gmail.com
}

Data de submissão: set. 2018 - Data de aceite: out. 2018 http://dx.doi.org/10.5335/rdes.v14i3.8586 
1974/1989) ${ }^{1}$ tomados em contraponto com suas Últimas aulas no Collège de France (1968 e 1969) (2012/2014) $)^{2}$, busquei compreender, como um todo, a ideia de Benveniste de uma "semiologia da língua", o que envolve a noção de interpretância e, consequentemente, as noções de semiótico e semântico formuladas e apresentadas, sobretudo, em A forma e o sentido na linguagem (texto de 1966/1967) ( $^{3}$ e em Semiologia da língua (texto de 1969).

Na reflexão que proponho agora, trato especificamente das noções de semiótico e semântico, mostrando que Benveniste as mobiliza de uma perspectiva linguística e de uma perspectiva semiológica. Além disso, procuro estabelecer uma relação entre o final programático proposto por Benveniste no artigo Semiologia da língua e essas noções. Nesse sentido, busco, em especial, a relação da metassemântica com a distinção semiótico/semântico.

Eis, portanto, os aspectos presentes em "Semiologia da língua" que, relacionados a outros textos do linguista (dos Problemas e, também, de suas Últimas aulas), passo a discutir.

\section{As noções de semiótico} e semântico de uma perspectiva linguística e de uma perspectiva semiológica

Considerando as formulações de Benveniste sobre a questão da dupla significância da língua, é possível perceber que o "contexto de aparecimento" da distinção semiótico/semântico em $A$ forma e o sentido na linguagem e em "Semiologia da língua" não é absolutamente o mesmo.

Em A forma e o sentido na linguagem, os interlocutores de Benveniste são filósofos e seu ponto de vista é linguístico; em Semiologia da língua, de outro modo, seus interlocutores são linguistas, seus próprios pares, e seu ponto de vista é semiológico. E é, segundo Flores (2013), essa mudança de perspectiva - linguística no artigo de 1966/1967, semiológica no de 1969 - que explica o diferente estatuto da distinção semiótico/semântico nesses textos ${ }^{4}$.

A constatação dessa mudança traz um problema para a discussão: essa diferença de estatuto implica também que, nesses textos, as noções de semiótico e semântico não têm o mesmo sentido? Problema esse que demanda algumas considerações.

A reflexão a respeito da questão da significância da língua é introduzida no artigo Os níveis da análise linguística $(1962 / 1964)^{5}$ (com a delimitação do domínio da língua como sistema de signos e do domínio da língua como instrumento de comunicação) e aprofundada nos artigos A forma e o sentido na linguagem $\mathrm{e}$ Semiologia da língua (com a formulação das noções de semiótico e semântico). Saliento que é o próprio linguista quem relaciona esses três textos através de uma nota em Semiologia da língua, estabelecendo, entre eles, um eixo condutor, ou seja, mais do que uma simples relação. 
Tanto em A forma e o sentido na linguagem quanto em Semiologia $d a$ língua, o semiótico se refere ao mundo fechado dos signos da língua, ou seja, à significância da língua-sistema. As relações que se estabelecem entre os signos são paradigmáticas, fazendo com que cada signo da língua tenha, sempre, um valor genérico e conceitual, devendo ser reconhecido. Por sua vez, o semântico se refere à significância da língua em seu funcionamento discursivo, ou seja, à significância da língua-discurso. As relações não se estabelecem mais entre os signos, mas entre as palavras, e são sintagmáticas, fazendo com que cada palavra tenha, sempre, um valor particular, específico e circunstancial, devendo ser compreendida.

Benveniste conclui, então, que a língua comporta dois domínios distintos, sendo que cada um deles exige seu próprio aparelho conceitual. O semiótico se baseia na teoria saussuriana do signo; o semântico necessita de um aparelho novo de conceitos e de definições, que concerne à reflexão do linguista a respeito da enunciação.

Mas, afinal, e a diferença de estatuto da distinção semiótico/semântico em $A$ forma e o sentido na linguagem e em $S e$ miologia da língua? O que essa diferença significa efetivamente, uma vez que há uma sinonímia entre essas noções de um texto para o outro?

Acredito que a mudança de perspectiva apontada por Flores (2013) - linguística no artigo de 1966/1967 e semiológica no de 1969, repito - mostre a função, o papel, da distinção semiótico/semântico nesses textos.

Em A forma e o sentido na linguagem, interessa pensar linguisticamente como a língua significa. Em Semiologia da língua, por sua vez, interessa pensar semiologicamente como a língua significa os outros sistemas, o que se dá a partir do modo como ela mesma significa.

Lembro que, nesse texto, Benveniste estabelece que "não menos que os sistemas de signos, as RELAÇÕES entre estes sistemas constituirão o objeto da semiologia" (1969/1989, p. 51). Segundo ele, "o problema central da semiologia" é "o estatuto da língua em meio aos sistemas de signos" (1969/1989, p. 51), o que o faz, em relação à semiologia, propor bem mais do que Ferdinand de Saussure no Curso de linguística geral, uma vez que cabe à semiologia estudar não apenas os sistemas semiológicos em si, mas também as relações entre os sistemas de signos, e a língua tem aí um papel fundamental.

Com isso, no texto de 1969, as noções de semiótico e semântico são mobilizadas - o que é bastante importante - em relação à língua, de um lado, e em relação aos sistemas não linguísticos, de outro.

Em relação à língua, como observado, não há diferença de sentido entre semiótico e semântico de um texto para o outro. Entretanto, em relação aos sistemas não linguísticos (discutidos apenas em "Semiologia da língua"), não é possível afirmar o mesmo. 
Em sua reflexão semiológica, comparando os diferentes sistemas (linguísticos e não linguísticos), Benveniste opera com as noções de semiótico e semântico. Nessa comparação, o linguista estabelece que, diferentemente da língua, os sistemas não linguísticos têm uma significância unidimensional, na medida em que não articulam, ao mesmo tempo, semiótico e semântico, mas apresentam apenas semiótico ou apenas semântico.

Isso não é tudo, no entanto. Em sua análise da estrutura e do funcionamento desses sistemas, Benveniste mostra que as noções de semiótico e semântico não se configuram como se configuram na língua. Ou seja, embora os termos empregados sejam os mesmos, o semiótico e o semântico da língua não correspondem ao semiótico nem tampouco ao semântico desses sistemas. Penso, nesse contexto específico, em suas observações a propósito da música e das artes, por exemplo.

Nessa perspectiva, a diferença de estatuto da distinção semiótico/semântico em A forma e o sentido na linguagem e em Semiologia da língua mostra que o pensamento de Benveniste sobre a questão da significância da língua envolve tanto uma reflexão linguístico-enunciativa a respeito da língua (do modo como a língua significa) quanto uma reflexão semiológica a respeito da relação da língua com os outros sistemas semiológicos (do modo como a língua significa os outros sistemas). E esta última diz respeito a sua "semiologia da língua".
Gostaria, ainda, de apontar que Benveniste trata das noções de semiótico e semântico no artigo "Estruturalismo e linguística", a entrevista dada a Pierre Daix, em julho de 1968, em Les Lettres françaises, assim como, ao longo do ano de 1969, em algumas de suas aulas no Collège de France, estabelecidas geneticamente na publicação Últimas aulas.

Em Estruturalismo e linguística, em uma reflexão na qual defende que "o homem não nasce na natureza, mas na cultura" e que nenhuma "língua é separável de uma função cultural” (BENVENISTE, 1968/1989, p. 23-24), o linguista apresenta as noções de semiótico e semântico (e os termos), sustentando não apenas que "a língua é o domínio do sentido", da simbolização, (BENVENISTE, 1968/1989, p. 25), mas ainda que a cultura consiste em um sistema de valores "que se imprimem na língua"6 (BENVENISTE, 1968/1989, p. 22).

Com isso, Benveniste mostra que a língua, assim como a cultura, envolve um sistema de valores que devem ser reconhecidos e compreendidos. Ou seja, o linguista mobiliza as noções de semiótico e semântico para pensar a língua (um sistema linguístico) e, também, a cultura (envolvendo sistemas não linguísticos), o que ilustra, em relação à língua, por exemplo, através da diferença em francês entre rôle (que significa algo) e ril (que não significa nada), de um lado, e rôle significando "le rôle [o "papel"] da ciência no mundo, le rôle [o "papel"] de tal ator" (BENVENISTE, 1969/1989, 
p. 22), de outro. E, em relação à cultura, através do sentido atribuído à cor branca no ocidente - "cor da luz, da alegria, da juventude" - e na China - "cor do luto" (BENVENISTE, 1968/1989, p. 22). Um parêntese: nessa mesma perspectiva, aliás, em A forma e o sentido na linguagem, lembro que Benveniste se refere à diferença entre chapeau / chameau e chareau em francês ("chapéu" e "chaméu", na tradução brasileira).

Em Estruturalismo e linguística, por conseguinte, Benveniste reflete a respeito de diferentes sistemas a partir das noções de semiótico e semântico, apresentando, como em Semiologia da língua, um ponto de vista semiológico. Sua discussão, no entanto, não se centra no que distingue a língua desses outros sistemas - a dupla significância da língua - nem tampouco se volta para a questão da metassemântica ${ }^{7}$.

Benveniste aponta, nesse momento, uma perspectiva referida, mais tarde, no texto de 1969, mas desenvolvida, de fato, no artigo Estrutura da língua e estrutura da sociedade, de outubro de 1968: a questão da língua como interpretante da sociedade, o que envolve um outro princípio norteador, o axioma "a língua contém a sociedade".

$\mathrm{E}$ faz isso explorando diferentes empregos da palavra homem - "o homem honesto" na cultura clássica francesa; "eu sou seu homem" na época feudal -; exemplo que coloca a língua, nas palavras do linguista, como reveladora da cultura, da espessura da cultura (BENVENISTE, 1969/1989, p. 22-23).
Por sua vez, como mostram suas Últimas aulas, Benveniste (1968/2014, p. 90, grifo do autor) inicia sua reflexão no Collège de France com uma afirmação - "Falar da 'linguística' é falar da língua" - e uma tomada de posição:

Nós propomos que a natureza essencial da língua, que comanda todas as funções que ela pode assumir, é sua natureza significante. Ela é informada de significância, mesmo considerada fora de qualquer emprego, de qualquer utilização particular ou geral. Essa propriedade, se ela nos parece - e ela nos parece de fato - transcender todas as outras, comandará nosso discurso sobre a língua: será um discurso sobre a característica que colocamos em primeiro plano: a língua significa (BENVENISTE, 1968/2014, p. 90, grifos do autor).

Partindo desse ponto de vista - que retoma, aliás, a ideia apresentada em $A$ forma e o sentido na linguagem de que "bem antes de servir para comunicar, a linguagem serve para viver" (BENVENISTE, 1967/1989, p. 222, grifo do autor) -, Benveniste explica que os elementos da língua, os signos, também "compartilham desse caráter significante que é próprio da língua em seu conjunto" e propõe "uma possível definição da linguística: ciência que se ocupa dos signos linguísticos" (BENVENISTE, 1968/2014, p. 91, grifo do autor).

O autor observa que a noção de signo é antiga, mas que "a ideia de que os signos podem formar conjuntos coerentes, sistemas de signos, e que eles propiciam o aparecimento de uma nova ciência, a ciência dos signos, a semiologia", "começa a emergir como uma das noções mais novas e mais importantes da ciência", o 
que conduz a "um problema maior, que abarca a linguística e além dela" (BENVENISTE, 1968/2014, p. 91, grifos do autor). Daí por que, na sequência, Benveniste apresenta os dois pensadores aos quais atribui "o verdadeiro nascimento" da teoria geral dos signos, apenas vislumbrada por John Locke (1632-1704), Charles Peirce e Ferdinand de Saussu$\mathrm{re}^{10}$ (BENVENISTE, 1968/2014, p. 92).

Nessa Primeira aula (de 2 de dezembro de 1968), portanto, embora não faça qualquer referência às noções de semiótico e semântico, Benveniste já introduz o termo e a noção de significância da língua.

Por outro lado, no decorrer de 1969, o linguista primeiro introduz as noções de semiótico e semântico e, depois, os termos em sua exposição no Collège de France.

Assim, na Aula 7, em uma reflexão a respeito da língua e dos sistemas não linguísticos (em especial sobre os sons e as cores), Benveniste (1969/2014, p. 121) coloca: "Começo a duvidar de que a língua pertença realmente à semiótica. Não seria ela somente o interpretante de todos os sistemas semióticos?". E faz isso na medida em que reconhece que há uma diferença, "a principal", para ele, entre a língua e os sistemas semióticos: "nenhum sistema semiótico é capaz de se tomar, ele próprio, como objeto, nem de se descrever em seus próprios termos" (BENVENISTE, 1969/2014, p. 120, grifos do autor).
Estabelecendo, então, que uma "distinção de base entre sistemas deve ser respeitada" - sistemas "que são autônomos", de um lado, e sistemas "que têm necessidade de um interpretante", de outro (BENVENISTE, 1969/2014, p. 121 [nota de ouvinte]) -, o linguista sustenta, em relação ao sistema da língua, que:

Há dois modos de significância, característica que parece não estar em nenhuma outra parte. Contrariamente ao que Saussure pensava, essa é uma propriedade que coloca a língua fora dos sistemas semiológicos ${ }^{11}$ :

1) cada signo é constituído por uma relação de significante com significado. Nas unidades de base, a significância já está incluída: ela é constitutiva dessas unidades;

2) essas unidades são agrupadas; só funcionam em conjunto. O princípio desse funcionamento é o segundo modo de significância.

A significação é, na língua, organizada em dois níveis (BENVENISTE, 1969/2014, p. 122 [nota de ouvinte]).

Eis as noções lançadas (o primeiro item corresponde à estrutura da língua; o segundo, a seu funcionamento), porém, ainda não nomeadas, o que ocorre, de fato, somente em sua última aula (a Primeira aula do terceiro capítulo).

Nessa aula, a primeira e única do ano letivo de 1969-1970, o linguista inicia seu curso retomando a reflexão desenvolvida no ano anterior. Discutindo a questão da significação, os problemas do sentido, na linguística, Benveniste recupera a noção saussuriana de língua - "um sistema de signos" -, assim como sua ideia de que "existem vários sistemas de signos e que se deve confiar seu estudo a uma nova ciência, a semio- 
logia", mas afirma categoricamente: "É preciso partir daqui para ir mais longe" (BENVENISTE, 1969/2014, p. 189, grifos do autor).

Nesse contexto, Benveniste salienta que Saussure coloca o signo linguístico "no mesmo plano que os signos não significantes dos outros sistemas", de onde sua ideia (de Benveniste) "de que basta que o signo seja reconhecido como pertencente à língua [...] e basta que 0 gesto seja reconhecido" (BENVENISTE, 1969/2014, p. 189-190, grifos do autor); o que também afirma, como mencionado, em "Estruturalismo e linguística", referindo-se à língua e à cultura.

$O$ linguista igualmente afirma que “é impossível passar do 'signo' à 'frase”, pois a "enunciação não é uma acumulação de signos: a frase pertence a uma outra ordem de sentido" (BENVENISTE, 1969/2014, p. 189, grifos do autor $)^{12}$. E acrescenta:

Podemos distinguir duas noções, onde, até agora, havia apenas uma, quando falávamos em semiótico.

1) A de estrutura formal semiótica dada pelas noções de "signo" e de "sistema de signos";

2) A de funcionamento semiótico, ausente da concepção saussuriana da língua. Se a língua pode ser um interpretante geral, é porque não é apenas um sistema no qual manejamos signos. Trata-se do único sistema no qual podemos formar frases (BENVENISTE, 1969/2014, p. 191 [nota de ouvinte]).

A partir dessa reflexão, que retoma e aprofunda o que é posto a respeito dos dois modos de significância na Aula 7, Benveniste define que são "como o se- miótico todos os sistemas que consistem em oposições em um conjunto fechado: as classificações, taxinomias, sinais etc.”, inclusive a língua, e que a

[...] esse sistema se opõe na língua um outro sistema (seria mesmo um sistema?), este do querer-dizer que está ligado à produção e à enunciação das frases, o semântico ${ }^{13}$ (BENVENISTE, 1969/2014, p. 191, grifos do autor).

Desse modo, como em Semiologia da lingua, em Estruturalismo e linguística e em suas aulas no Collège de France, a distinção semiótico/semântico é mobilizada (tanto em relação à língua quanto em relação aos sistemas não linguísticos) em uma perspectiva semiológica. Além disso, em Estruturalismo e linguísti$c a$, sobre essa distinção, Benveniste (1968/1989, p. 22) reitera que se trata de "um ponto de vista [...] pessoal, que precisa ser demonstrado", exigindo, segundo ele, a elaboração de "todo um corpo de definições neste imenso domínio, que não compreende somente a língua", e que o leva à cultura. Ou seja, mais uma vez, o linguista considera a língua e os sistemas não linguísticos (a cultura), e uma perspectiva semiológica é mobilizada.

De outro modo, em relação à língua ainda, se, na Aula 7, o linguista se refere a uma organização da significação em níveis, nessa sua última aula (a Primeira aula do terceiro capítulo, lembrando), Benveniste aponta "uma distinção entre dois mundos e duas linguísticas" (1969/2014, p. 191); como faz, aliás, respondendo a Piguet no debate que segue "A forma e o sentido na linguagem". 


\section{A distinção semiótico/ semântico e o final programático do artigo "Semiologia da língua"}

Retomo, neste momento, o final programático proposto por Benveniste em Semiologia da língua, apresentando, em seguida, algumas considerações a respeito de sua relação com as noções de semiótico e semântico.

Em conclusão, é necessário ultrapassar a noção saussuriana do signo como princípio único, do qual dependeria [sic] simultaneamente a estrutura e o funcionamento da língua. Esta ultrapassagem far-se-á por duas vias:

- na análise intralinguística, pela abertura de uma nova dimensão de significância, a do discurso, que denominamos semântica, de hoje em diante distinta da que está ligada ao signo, e que será semiótica;

- na análise translinguística dos textos, das obras, pela elaboração de uma metassemântica que se construirá sobre a semântica da enunciação. Esta será uma semiologia de "segunda geração", cujos instrumentos e o método poderão também concorrer para o desenvolvimento das outras ramificações da semiologia geral (BENVENISTE, 1969/1989, p. 67).

A compreensão da dupla dimensão de significância da língua (que resulta na formulação do par, da distinção, semiótico/semântico) permite a Benveniste, de um lado, desenvolver sua semântica da enunciação, que implica uma análise intralinguística, e, de outro, propor seu projeto apenas anunciado de uma semiologia de segunda geração ou metassemântica, tendo como base a semântica da enunciação, e não o signo de Saussure, em uma análise translinguística dos textos e das obras.

$\mathrm{E}$ é, desse modo, tanto através da semântica da enunciação quanto através da metassemântica (as "duas vias"), que se fará, para o linguista, a necessária ultrapassagem da noção saussuriana do signo como princípio único de explicação da significação da língua. Isso porque, se, a partir do signo saussuriano, se explica a significância relacionada à estrutura da língua, nada se diz a respeito daquela relacionada a seu funcionamento, ou melhor, daquela que relaciona simultaneamente sua estrutura e seu funcionamento. Afinal, quando se pensa a língua em funcionamento, semiótico e semântico se encontram intrinsecamente ligados.

Trata-se, portanto, de uma ultrapassagem em relação ao proposto por Saussure, que centra sua reflexão na noção de signo e na ideia de língua como sistema, estrutura. Ultrapassagem, nesse contexto, para Benveniste, acredito, sobretudo no sentido de se deixar de pensar que, apenas com Saussure, seja possível compreender a questão da significância da língua, sua propriedade de significar.

Para mim, contudo, se se deseja falar em ultrapassagem (e digo isso porque muito se fala nesta questão relacionando Benveniste e Saussure), é a noção benvenistiana de língua, articulando semiótico e semântico, ou seja, ao mesmo tempo, estrutura e funcionamento linguísticos, que se configura, de fato, em um "ir além" do proposto por Saussure ${ }^{14}$, pois é 
essa concepção de língua que possibilita as "duas vias" apresentadas e defendidas por Benveniste. Os dois pontos de vista a partir dos quais se deixa, então, a noção saussuriana do signo como princípio único de explicação da significância da língua: um linguístico, a semântica da enunciação, e outro semiológico, a metassemântica.

Com isso, em Semiologia da língua, entendo que o linguista opera com as noções de semiótico e semântico e, a partir delas, com a noção de interpretância não apenas no que se refere à relação da língua com os outros sistemas, mas também com a metassemântica ${ }^{15}$.

Isso porque, na análise translinguística proposta por Benveniste, os textos e as obras não são tomados da perspectiva do signo (como ocorre em outros estudos do campo da semiologia/semiótica da época ${ }^{16}$ ), mas seriam tomados de uma perspectiva na qual a língua, sistema interpretante, interpreta textos e obras, sistemas interpretados.

Seguindo essa ótica, acredito que esses sistemas interpretados envolveriam não apenas os sistemas não linguísticos (como a pintura, desenho, escultura, sistemas que, conforme o linguista, apresentam uma semiótica própria criada pelo artista e que dependem, portanto, da língua para existir (BENVENIST, 1969/1989, p. 59-61)), mas também os sistemas linguísticos cuja significância, à semelhança do que ocorre na arte, "é posta pelo autor na obra", sendo descoberta "NO INTERIOR de uma composição", uma obra sempre particular (BENVENISTE, 1969/1989, p. 60, grifo do autor).

Estendo aqui, desse modo, a reflexão de Benveniste a respeito do não linguístico (em particular, sua reflexão sobre as artes figurativas) ao linguístico produzido artisticamente. Seriam esses, acredito, os textos e as obras referidos nessa parte final do artigo; o que faria, por exemplo, tanto de uma obra pintada quanto de uma obra literária o objeto da metassemântica em uma análise translinguística.

Observo contudo que literário, nessa perspectiva, não corresponde absolutamente a uma perspectiva própria ao campo da literatura, mas ao linguístico produzido artisticamente. Ou seja, a um linguístico cujo semântico não se configura na relação com um semiótico que articula, a grosso modo, para cada interlocutor, os mesmos valores de referência (um sistema compartilhado), mas na relação com um semiótico específico produzido pelo autor/escritor/artista (o que envolveria, em especial, textos considerados literários). Daí, acredito, a denominação conferida, por Benveniste, a seu estudo sobre a linguagem poética: a língua de Baudelaire ${ }^{17}$.

E, nesse sentido, como Flores (2013), também penso que haveria uma relação entre textos e obras, em Semiologia da língua, e o que Benveniste denomina "as grandes unidades"18, em "Esta linguagem que faz a história" (1968), ou "formas complexas do discurso"19, em $O$ aparelho formal da enunciação (1970). 
Hipóteses (e, por isso, o uso do condicional) cuja comprovação ou refutação, aliás, dificilmente ocorrerá, uma vez que se trata de um projeto apenas anunciado pelo linguista.

Acredito, no entanto, que essa possibilidade de leitura encontre amparo nas diferentes referências que o linguista faz, ao longo de sua reflexão em Semiologia da língua, aos sistemas unidimensionais, como os da música e da pintura, em especial, quando se refere positivamente aos estudos que inauguram "uma 'leitura' semiológica da obra pintada”, propondo "uma análise análoga àquela de um 'texto"' (BENVENISTE, 1969/1989, p. 61 , nota 25 , grifos do autor $)^{20}$.

\section{Considerações finais}

A partir do exposto, é possível constatar que, efetivamente, as noções de semiótico e semântico (noções que configuram a dupla significância da língua), são fundamentais na reflexão desenvolvida por Benveniste - uma reflexão linguística, ou seja, a respeito do modo como a língua significa, mas também uma reflexão semiológica, ou seja, a respeito do modo como a língua significa os outros sistemas semiológicos. Diversos textos de Benveniste mobilizam, de um modo ou outro, a distinção semiótico/ semântico, mostrando essas diferentes perspectivas, uma linguística e outra semiológica.

De outro modo, o final programático proposto por Benveniste em "Semiologia da língua" está estreitamente relacionado com as noções de semiótico e semântico. Inclusive a noção de metassemântica, conforme a leitura que apresentei.

Lembro, por fim, do que Claudine Normand afirma em relação a Saussure e a um "efeito" Saussure -

Em todos os casos, só se pode esperar uma reconstituição, logo, uma interpretação. Se for para buscar a última palavra de uma teoria e a verdade de um pensamento, é melhor renunciar a Saussure (2004a, p. 169).

Assim como, digo eu, a Benveniste! Trago aqui, portanto, apenas uma possibilidade de leitura desses aspectos presentes em Semiologia da língua para uma discussão de seu pensamento.

\section{Émile Benveniste and the double significance of language: the semiotics/ semantics distinction}

\section{Abstract}

This study deals specifically with the double significance of language, that is, the notions of semiotics and semantics developed by Émile Benveniste in the articles "Form and Meaning in Language" (1967; 1974) and "Semiology of Language" (1969; 1974). It aims to, on the one hand, discuss the semiotics/semantics distinction (highlighting it from a linguistic and from a semiological perspective) and, on the other hand, to establish a relation between the programmatic ending proposed by the linguist in "Semiology of Language" and the notions of semiotics and semantics. In order to do so, in addition to the 
cited articles, other texts of Problems in General Linguistics (1966/1995; 1974/1989) are brought into use in contrast with the publication Dernières Leçons. Collège de France 1968 et 1969 [Last Lectures at Collège de France (1968 and 1969)] (2012/2014), work established genetically, based on manuscripts by the linguist and by his students.

Keywords: Émile Benveniste. (Double) Significance. Semiotics. Semantics. Semiology of language.

\section{Notas}

1 Daqui para frente, também, apenas Problemas.

2 Daqui para frente, também, apenas Ultimas aulas.

3 Conferência proferida por Benveniste em Genebra, em 1966, no XIII Congresso das Sociedades de Filosofia de Língua Francesa, posteriormente publicada, em 1967, em Le langage II e, em 1974, na quinta parte - "O homem na língua" - do segundo volume dos Problemas.

4 Laplantine (2011, p. 80) observa que, entre a escrita de "A forma e o sentido na linguagem" e de "Semiologia da língua", "há o trabalho sobre a língua poética de Baudelaire". Para a autora, inclusive, "Semiologia da língua" "não teria sido possível sem essa poética" (LAPLANTINE, 2011 , p. 81), uma vez que o problema da arte constitui o cerne do questionamento de Benveniste nesse artigo. A questão da arte ocupa, de fato, um lugar importante nessa reflexão do linguista, mas, se Benveniste examina sistemas não linguísticos (o sistema da música e o das artes plásticas, em particular), acredito que seu propósito seja o de esclarecer "como a língua significa" para explicar por que se constitui no "interpretante de todos os sistemas semióticos". Não concordo, por conseguinte, com a leitura de Laplantine (2011, p. 72, grifos da autora, tradução minha) de "uma conversão do ponto de vista" que teria transformado toda a teoria da linguagem de Benveniste a partir de seu trabalho sobre a linguagem poética.

5 Conferência proferida por Benveniste em Cambridge, em 1962, no $9^{\circ}$. Congresso Internacional de Linguística, posteriormente publicada em três momentos: em 1962, depois em 1964, em Proceedings of the $9^{\text {th }}$ International Congress of Linguists, e, mais tarde, em 1966, na terceira parte - "Estruturas e análises" - do primeiro volume dos Problemas. Saliento ainda que a perspectiva adotada no texto de 1962/1964, assim como no de 1966/1967, é linguística.

6 Essas afirmações a respeito da relação entre língua (domínio do sentido) e cultura (sistema de valores que se imprimem na língua), o princípio de que "o homem não nasce na natureza, mas na cultura" (BENVENISTE, 1968/1989, p. 23) e o de que é "um homem falando que encontramos no mundo, um homem falando com outro homem" (BENVENISTE, 1958/1995, p. 285) mostram como o viés antropológico, estruturante da teoria da linguagem de Benveniste, opera em sua reflexão semiológica. Ponto de vista defendido pelo linguista, por exemplo, em "Da subjetividade na linguagem" (1958) e reiterado em "Semiologia da língua": "A significância da língua [...] é a significância mesma, fundando a possibilidade de toda troca e de toda comunicação, e também de toda cultura" (BENVENISTE, 1969/1989, p. 60).

7 Aspectos tratados no artigo de 1969.

8 Conferência proferida por Benveniste em Milão, em 1968, no encontro Linguaggi nella società e nella técnica, posteriormente publicada, em 1970, pela Edizioni di Comunità e, em 1974, na terceira parte - "Estruturas e análises" - do segundo volume dos Problemas.

9 Trata-se, então, de um problema que envolve, sim, uma reflexão linguística, mas que não se limita a ela, pois, para além da linguística, envolve igualmente uma reflexão semiológica. Relaciono essa consideração de Benveniste às "duas vias", propostas no final de "Semiologia da língua”, através das quais se fará, segundo o linguista, a necessária ultrapassagem da noção saussuriana do signo como princípio único de explicação da significação da língua: a semântica da enunciação (uma análise intralinguística, ou seja, no campo da linguística, mas além do signo) e a metassemântica (uma análise translinguística, ou seja, que se estende "além dela [linguística]”) (BENVENISTE, 1969/1989, p. 67). Retomo essa questão na segunda parte deste trabalho.

10 Mesmo movimento da primeira parte de "Semiologia da língua”, o que mostra, aliás, a sintonia existente entre o artigo, de um lado, e suas aulas a respeito da semiologia no Collège de France, de outro. 
11 Essa passagem (proveniente das notas dos ouvintes) encerra a Aula 7 e responde à passagem anterior que questiona o pertencimento da língua à semiótica (proveniente, por sua vez, das notas do próprio linguista). Com essa discussão, Benveniste não refuta, acredito, o fato de a língua ser um sistema semiótico, mas estabelece que, por suas características que não se encontram em nenhum outro sistema, a língua tem uma função específica em relação a esses sistemas: a de interpretante; sendo, aliás, o que faz dela o sistema mais importante. Esse questionamento reaparece na Primeira aula do terceiro capítulo, quando o autor questiona se o semântico seria mesmo um sistema, o que aponto a seguir.

12 Aproveito essas duas passagens para uma observação. Acredito que, como outras, essas passagens ilustram como a discussão de Benveniste se sobrepõe em seus textos que datam dos anos 60 , sobretudo naqueles da segunda metade da década. Nesse momento, por exemplo, é retomada a ideia do hiato, apresentada em "Semiologia da língua", assim como a definição de frase, formulada em "A forma e o sentido na linguagem". Lembro que essa última aula ocorre em $1^{\circ}$. de dezembro de 1969.

13 Laplantine, em "Faire entendre Benveniste" (2013), comenta a forma como essa passagem foi estabelecida por Coquet e Fenoglio. Laplantine (2013, p. 8, tradução minha) observa que "na língua" está em destaque nos manuscritos, "o que sublinha a especificidade da língua" e que a palavra "semântico", em destaque (em itálico) no texto estabelecido, foi acrescentada pelos organizadores. Ao que tudo indica, portanto, nos manuscritos dessa aula, o termo "semântico" aparece, de fato, apenas na parte proveniente dos ouvintes de Benveniste. É importante esse registro. Não acredito, porém, que isso mostre uma incoerência em relação ao pensamento do linguista apresentado em "A forma e o sentido na linguagem", "Estruturalismo e linguística" ou "Semiologia da língua". Convém, no entanto, ressaltar a peculiaridade editorial de suas Últimas aulas. Não se trata de um texto assinado por Benveniste, mas de um texto estabelecido geneticamente por Jean-Claude Coquet e Irène Fenoglio a partir de manuscritos do linguista e de alguns de seus alunos no Collège de France. Daí por que se faz pertinente a indicação das passagens que provêm de seus alunos e não do próprio Benveniste; o que tomo o cuidado de fazer, ao longo de todo este trabalho, através da notação [nota de ouvinte].

14 Um "ir além não 'com' Saussure, mas 'a partir de' Saussure", eu diria, na medida em que Benveniste parte das ideias do mestre genebrino, fazendo, porém, deslocamentos importantes em relação a seu pensamento. Como a respeito da noção de signo, por exemplo, incluindo a noção de falante (em "A forma e o sentido na linguagem"). Ou seja, Benveniste dialoga com Saussure, mas produz algo seu no debate linguístico. Aliás, nessa perspectiva, com base na ideia de um "encontro" de Benveniste com Saussure (NORMAND, 2004b), Flores (2013, p. 50) afirma que "Benveniste toma Saussure como ponto de partida, mas não se encerra nele. Benveniste mantém, altera e mesmo nega Saussure para construir sua visão da linguagem. Então, é de um encontro de que se trata, no sentido mais amplo da palavra".

15 Há, nesse artigo igualmente, uma breve referência à escrita (que Benveniste informa tratar em outro momento), assim como considerações sobre a relação da língua com a sociedade.

16 Penso, por exemplo, no pensamento de Roland Barthes em L'aventure sémiologique (1985).

17 Dessons (2006), por outro lado, aponta que essa dimensão artística da linguagem está estreitamente relacionada com a questão da subjetivação, com o que, aliás, concordo. No entanto, como Laplantine (2011), Dessons atrela a distinção semiótico/semântico à reflexão de Benveniste sobre a arte em "Semiologia da língua", assim como à reflexão de Benveniste sobre o poema (a linguagem poética) nas notas que compõem o Dossiê Baudelaire, o que compreendo diferentemente. Parece-me ainda que Dessons não relaciona essa discussão de Benveniste a uma reflexão semiológica propriamente dita, envolvendo, inclusive, a proposição de uma metassemântica (anunciada no final do artigo de 1969), mas à busca de uma teoria da significância da arte (na qual se inscreve, mais tarde, segundo Dessons e Laplantine, a teoria do ritmo e a poética de Meschonnic (1982)).

18 O linguista associa "as grandes unidades" a "um discurso inteiro, um poema inteiro, nos quais se pode encontrar um sentido frequentemente muito distante do sentido literal", fazendo, nesse momento, uma analogia com a linguagem do inconsciente (BENVENISTE, 1969/1989, p. 36).

19 Benveniste (1970/1989, p. 90) associa as "formas complexas do discurso", por exemplo, à 
enunciação escrita, na qual "o que escreve se enuncia ao escrever e, no interior de sua escrita, ele faz os indivíduos se enunciarem".

20 Trata-se da nota de Benveniste sobre os trabalhos de Metz e Scheffer; nota que Barthes também comenta em "Por que gosto de Benveniste" (1974), sua resenha do segundo volume dos Problemas.

\section{Referências}

BARTHES, Roland (1974). Por que gosto de Benveniste. In: O rumor da língua. São Paulo: Editora Brasiliense, 1988. p. 179-183.

BARTHES, Roland. L'aventure sémiologique. Paris: Éditions du Seuil, 1985.

BENVENISTE, Émile (2012). Últimas aulas no Collège de France (1968 e 1969) (Orgs. Jean-Claude Coquet e Irène Fenoglio). São Paulo: Editora Unesp, 2014.

. (1966). Problemas de linguística geral I. Campinas: Pontes, 1995.

. (1974). Problemas de linguística geral II. Campinas: Pontes, 1989.

DESSONS, Gérard. Émile Benveniste, l'invention du discours. Paris: Éditions IN PRESS, 2006.

FLORES, Valdir do Nascimento. Introdução à teoria enunciativa de Benveniste. São Paulo: Parábola Editorial, 2013.

LAPLANTINE, Chloé. Faire entendre Benveniste. Acta Fabula (Dossier critique - Ce qui a fait signe \& ce qui fait sens), Paris, v. 14, n. 7 , p. 1-10, 2013.

LAPLANTINE, Chloé. La poétique d'Émile Benveniste: Benveniste et les "correspondances”. In: BRUNET, Émilie; MAHRER, Rudolf (Orgs.). Relire Benveniste: réceptions actuelles des Problèmes de linguistique générale. Bruxelles: Academia (Sciences du langage: carrefours et points de vue), 2011. p. 72-95.
MESCHONNIC, Henri. Critique du rythme. Anthropologie historique du langage. Paris: Lagrasse: Verdier/poche, 1982.

NORMAND, Claudine (2000). Saussure. Paris: Société d'édition Les Belles Lettres, 2004a.

NORMAND, Claudine. Saussure-Benveniste. Cahiers Ferdinand de Saussure, Genebra, n. 56, p. 125-132, 2004b.

ROSÁRIO, Heloisa Monteiro. Um périplo benvenistiano: o semiólogo e a semiologia $d a$ língua. 2018. 173 folhas. Tese (Doutorado em Estudos da Linguagem) - Programa de Pós-Graduação em Letras, Universidade Federal do Rio Grande do Sul, Porto Alegre, 2018.

SAUSSURE, Ferdinand de (1916). Curso de linguística geral. São Paulo: Editora Cultrix, 2006. 